\title{
Conductivity measurement of plaque samples obtained from the insulation of high voltage extruded cables
}

\author{
Hossein Ghorbani \\ Senior R\&D Engineer \\ ABB High Voltage Cables \\ Karlskrona, Sweden \\ hossein.ghorbani@se.abb.com
}

\author{
Andreas Farkas \\ Senior Principall R\&D Engineer \\ ABB High Voltage Cables \\ Karlskrona, Sweden \\ andreas.farkas@se.abb.com
}

\author{
Pierre Hulden \\ Test Engineer \\ ABB Power Products \\ Ludvika, Sweden \\ pierre.hulden@se.abb.com
}

\begin{abstract}
Good understanding of insulation conductivity is of great importance in development and design of high voltage DC cables. Conductivity of polymeric insulation materials is a property which is quite sensitive to many parameters such as temperature, electric field, chemical composition, thermal history, morphology, etc. Therefore, due to different process history, the results obtained from pressed plaques are not necessarily representative of the insulation behavior in an extruded cable. A method was developed to obtain samples from $\mathrm{HV}$ cable in form of plaques with a thicknesses up to a few millimeters. Plaque samples were extracted from two cables, their conductivity at high field was measured and compared to those obtained from fullscale tests; the results, confirm a very good agreement between the small scale and full-scale measurements; this hints to a promising prospect for such small scale characterization techniques.
\end{abstract}

\section{Introduction}

Within the field of extruded High Voltage DC cable technology, understanding of conduction phenomena in the dielectric materials is of paramount importance [1][2]. This is due to the simple fact that under steady state DC voltage, the electric field distribution in a dielectric is dictated by the conduction processes, unlike with AC where permittivity is usually a dominating property.

The first step in design of HVDC cables, usually is to characterize the conduction properties of the insulation material using different techniques. DC conduction measurement under controlled thermal conditions and high electric field is a common test technique which provides the level of conductivity and its dependence on different parameters such as temperature and electric field [1][3]. Although such tests are essential for comparison of different insulation materials, an underlying challenge and uncertainty exists in relating the results of small scale tests with real full-scale cables. Since different parts of cable insulation experience different thermal and chemical conditions during the extrusion, vulcanization, heat treatment, and even tests, the conductivity of insulation is not homogenous. In XLPE insulated cables, the temperature gradient during crosslinking, may affect the crosslinking reactions and also the resulting morphology in the inner and outer parts of insulation which in its turn affects conductivity of the insulation [4]. The XLPE cables usually undergo a heat treatment step, also called degassing, to remove the volatile chemicals produced from the decomposition of peroxides. Since the chemicals can only leave the insulation system through the outer interface, this leads to a gradient in the chemical content of the insulation. It is well-known that the polar by-products from peroxide decomposition, such as Acetophenone, Cumyl-Alcohol strongly affect the conduction processes and space charge formation in the insulation [5][6]. The gradient in the by-product content of the insulation will therefore have a considerable effect on the conduction processes in the insulation of extruded DC cables.

Beside the effect of volatile polar chemicals, conduction is sensitive even to morphology and Carbonyl content of the base polymer [7]. The picture become even more complicated considering the effect of crystallinity on diffusion properties of the polymer [8] and the effect of base polymer Carbonyl content on the solubility of polar chemicals [9]. Since all parameters mentioned above, i.e. by-product content and composition, morphology, Carbonyl content, etc., are not uniform throughout the insulation, it is very challenging to produce press molded samples which are representative of the real cable insulation. Instead one needs to focus on testing the real cable insulation; although the measurement of leakage current from the cable provides insight into the insulation conductivity, such results only provide an average value for conductivity of the cable insulation at different conditions. Space charge measurement using PEA technique can provide further insight into the distribution of conductivity in the insulation but it can be hard to achieve reliable PEA measurements in cables with thick insulation especially when temperature gradients exist throughout the insulation.

Considering the challenges above, since long, researchers have been interesting in testing samples obtained from full-scale cables [4] [10] [11] [12]. In this way, while enjoying the advantage of small scale lab condition tests, one obtains representative data from the actual cable insulation.

Despite the number of publications based on testing peeled samples from cables, in majority of studies, in order to obtain better reproducibility, the samples are degassed which will affect the results; specifically the DC conductivity. Therefore, in this work efforts have been paid on producing and testing samples from XLPE 
insulated cables while keeping the volatile chemicals in the sample to obtain results most representative of the real cable as possible. The sample extraction method is planned in a way to minimize the disturbance to the chemical and physical composition of the insulation. Samples from 2 different radiuses of 2 cables were tested under DC voltage with strictly controlled thermal conditions. The results were then compared to those obtained from full-scale testing of the cables.

\section{Experiments}

The experiments were conducted in 2 parts; in the first part, the reliability of the sample production method was evaluated by measuring its effect on the crosslinking by-products content of the sample; in the second part, the method was used to extract samples from 2 different radius of 2 cables, the conductivity of the samples were measured under high voltage DC and different thermal conditions; finally the results are compared to those obtained from full-scale testing of the cables with high voltage DC at different thermal conditions.

\subsection{Sample preparation method}

The choice of sample thickness is a trade-off between spatial resolution and minimal disturbance to the sample composition. In majority of existing publications, the studies were conducted on very thin 100-200 um thick films obtained from cable insulation by means of peeling [4][10][11][12]. The advantage of this method is that using a short piece of cable, it is possible to obtain samples from different locations of the insulation; besides, by voltage levels of few $\mathrm{kV}$, electric fields representative to HVDC cables can be achieved.

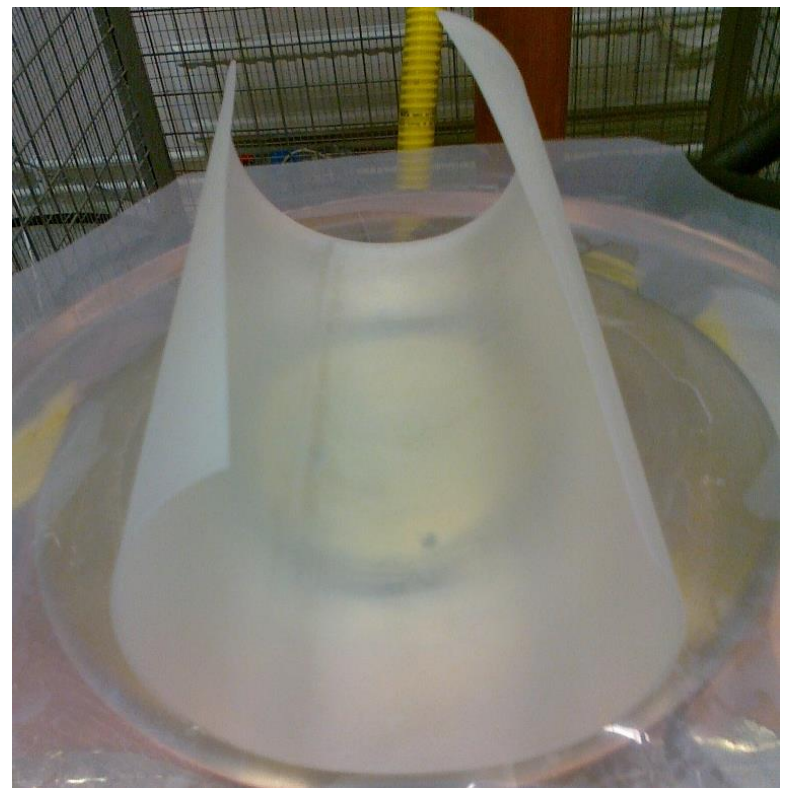

Fig. 1 - Produced cylindrical samples are cut open to obtain plate samples which can be tested using plate sample testing equipment.
The disadvantage of such techniques is that considerable amount of volatile chemicals may leave the sample during the sample production, handling and testing. In this work, $1 \mathrm{~mm}$ thick samples were produced by means of lathing and cable insulation from the inside and the outside until a $1 \mathrm{~mm}$ thick cylinder is remaining from the insulation which is cut open to obtain a plaque sample, see Fig. 1.

One of the main objectives of this technique has been not to disturb the chemical composition of the insulation during the sample extraction. Thermal investigations using Infrared (IR) camera (see Fig. 2) showed that the surface temperature of the sample will momentarily reach temperature between 60 to $70{ }^{\circ} \mathrm{C}$ just after being in contact with the lathing head, but it will cool down to room temperature in less than 20 seconds.

Since the surface of the final sample will experience this temperature for a short while, it was concluded that the effect on chemical composition will be minimal. The produced samples are then wrapped in Al-foil and stored in freezer $\left(<-5^{\circ} \mathrm{C}\right)$ until they are tested.

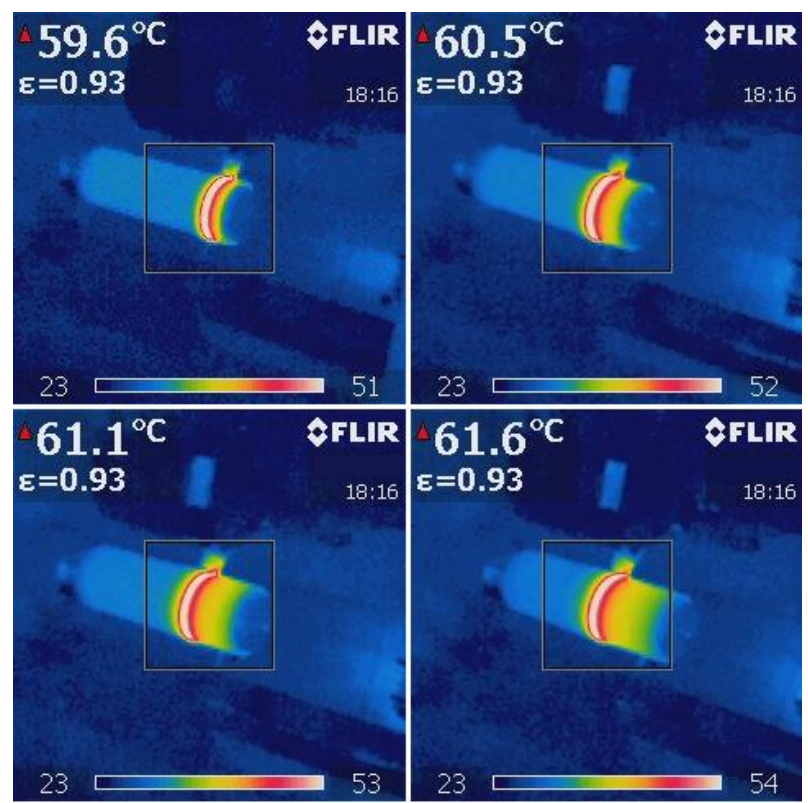

Fig. 2 - IR thermal camera pictures taken during lathing of a sample; the surface temperature momentarily may reach up to $65^{\circ} \mathrm{C}$ but it cools down to room temperature very fast.

\subsection{Effect on Cross-linking by-products}

To test the effect of production method on the chemical content of the produced samples, 3 samples were obtained from a full-scale cable with XLPE insulation. The samples were kept in freezer for around 1 week before the concentration of the major cross-linking byproducts (Cumyl-Alcohol, Acetophenone and AlphaMethyl-Styrene) were measured using Gas Chromatography (GC). The by-product concentration profile throughout the cable insulation was measured on a cable sample from the same cable length. As shown in Fig. 3, the by-product concentration of the samples were almost identical to those obtained from the cable 
sample. This further confirmed that using this method the disturbance in the chemical composition of the sample is minimal and the produced samples contain a similar chemical composition as the cable.

It is notable that the conclusion above is limited to the cross-linking by products such as Cumyl-Alcohol, Acetophenone and Alpha-Methyl-Styrene and other chemicals with diffusion constants in the same level or lower. Smaller molecules such as water with much higher diffusion constant, may be degassed even using this sample extraction method.

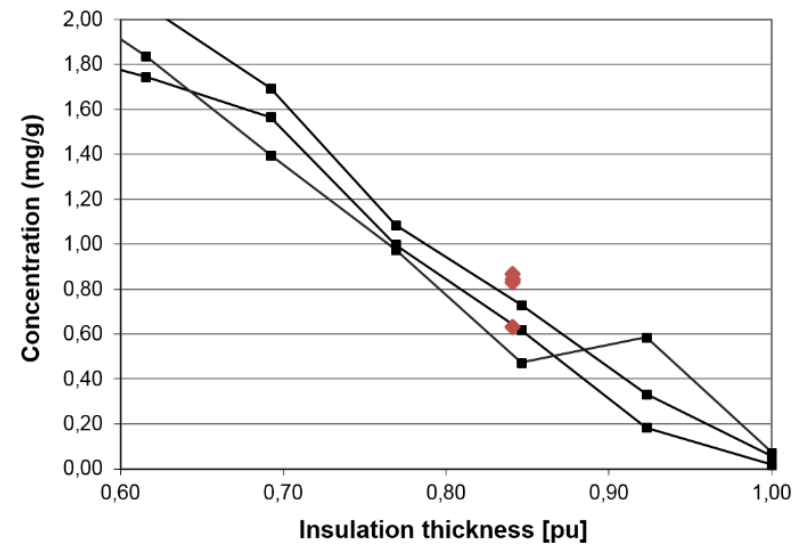

Fig. 3. - Black line: sum of the crosslinking by-products throughout the cable insulation measured by GC. Red: Sum of crosslinking by-products of plate sample extracted from the same cable by lathing.

\subsection{Samples from cables}

Samples were produced from 2 different cables (C1 and C2) each with a large conductor $\left(2000 \mathrm{~mm}^{2}\right.$ Aluminum) and $12 \mathrm{~mm}$ extruded XLPE insulation. Two radial positions from each cable (D1 and D2) was investigated (4 samples from each radius); D1, 1-2 $\mathrm{mm}$ from the inner semicon representing the inner part of the insulation; and D2 2-3 $\mathrm{mm}$ from the outer semicon representing the outer parts of the insulation. In this text, the samples will be referred to as C1-D1, C1-D2, C2-D1 and C2-D1. For each cable/radius 4 samples (in total 16 samples) were produced, but some tests were disrupted by surface flash-over and in this paper only the results of the successfully tested sample are provided.

\subsection{Conductivity measurements}

The samples were tested by applying high voltage while the electrode system was kept in an oven with strictly controlled thermal conditions [3]. At low temperature $30 \mathrm{kV}$ was applied on the sample, then the temperature was increased to $70{ }^{\circ} \mathrm{C}$ within 3 hours; the temperature was kept constant for $15 \mathrm{~h}$, then the set-up was slowly cooled down towards room temperature within $8 \mathrm{~h}$, see Fig. 4. The sample temperature during the whole period was logged using a PT100 sensor mounted to the guard electrode.

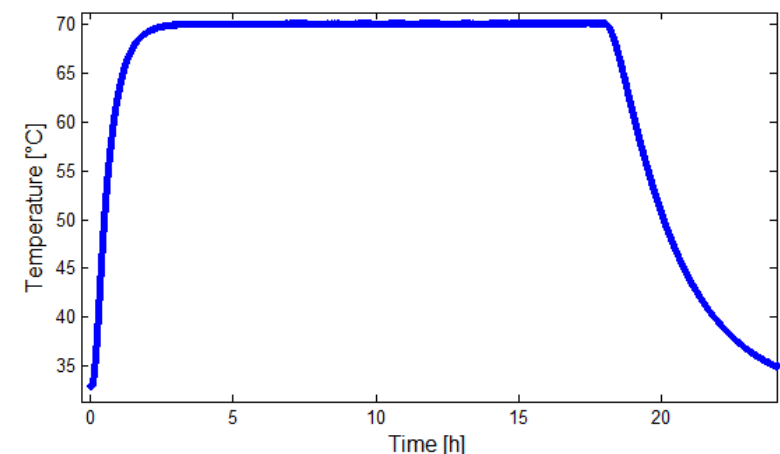

Fig. 4 - Temperature of the samples during the test measured at the guard electrode.

The apparent conductivity of the material can be calculated from the measured leakage current as:

$\sigma=\frac{I}{U} * \frac{d}{A}$

Eq. 1

Where $I$ is the current, $U$ is the voltage, $d$ is the sample thickness and $A$ is the measurement electrode area.

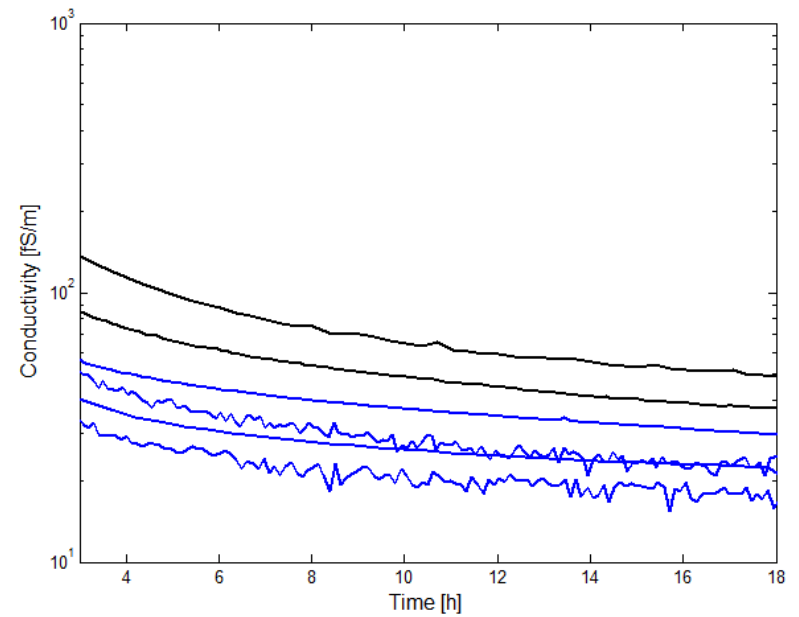

Fig. 5 - Apparent conductivity of samples from $\mathrm{C} 1$ at constant temperature $70{ }^{\circ} \mathrm{C}$; black: samples from D1; blue: samples from D2.

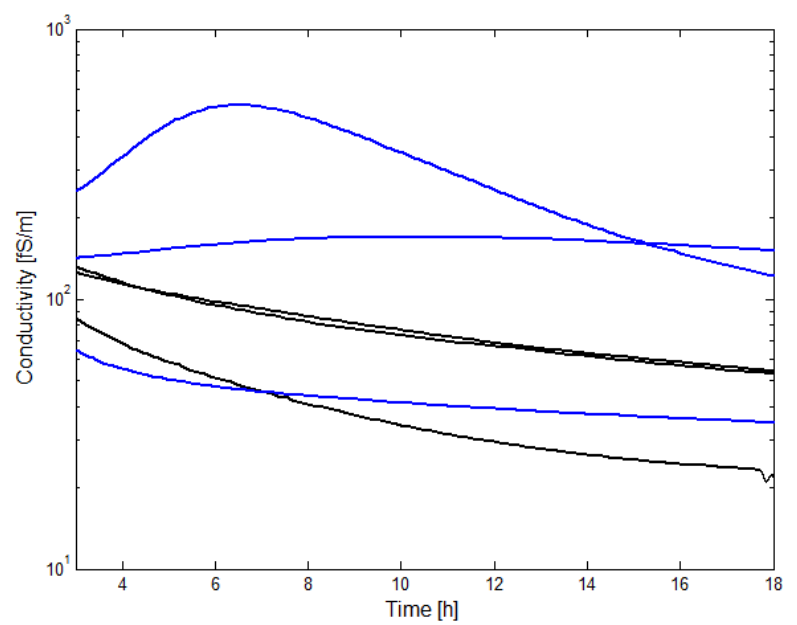

Fig. 6 -Apparent conductivity of samples from $\mathrm{C} 2$ at constant temperature $70{ }^{\circ} \mathrm{C}$; black: samples from D1; blue: samples from D2.

The measured apparent conductivity curve at isothermal conditions with $70{ }^{\circ} \mathrm{C}$ for $\mathrm{C} 1$ and $\mathrm{C} 2$ are shown 
respectively in Fig. 5 and Fig. 6 respectively. Generally, the apparent conductivity decays during the test period. C2 samples show higher apparent conductivity than those of $\mathrm{C} 1$. Interestingly, the two cables show a different trend in spatial distribution of conductivity; while $\mathrm{C} 1$ shows higher conductivity in the inner parts, $\mathrm{C} 2$ clearly shows higher conductivity at the outer parts. This means that both level and the profile of conductivity in these two cables is rather different.

Since the cooling is done very slowly, by plotting the apparent conductivity versus temperature in an Arrhenius plot, it is possible to judge the temperature dependence of conductivity, as shown in Fig. 7 and Fig. 8 respectively for $\mathrm{C} 1$ and $\mathrm{C} 2$.

The results again confirm the difference in the spatial distribution of conductivity in the two cables. Besides, the temperature dependence of $\mathrm{C} 2$ in the inner and outer parts is rather different (note the slope of the lines in Fig. 8).

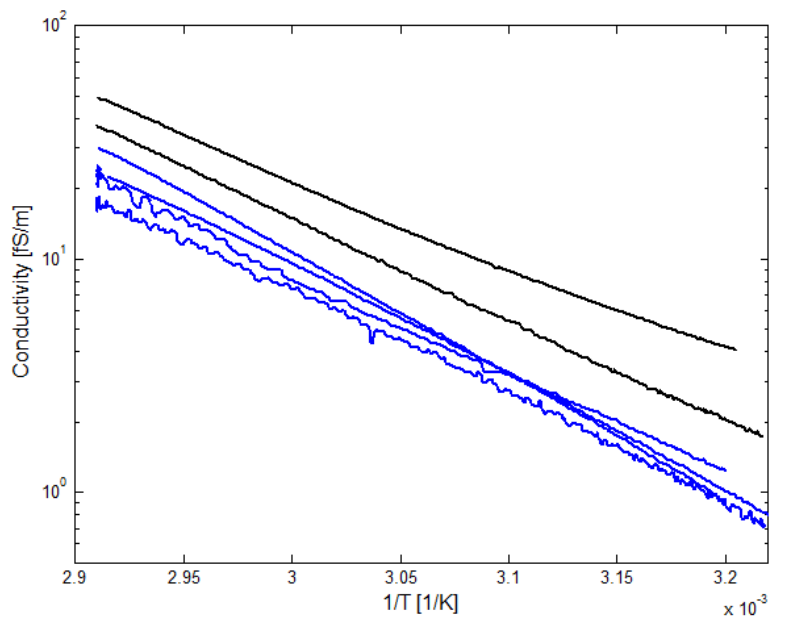

Fig. 7 - Arrhenius plot of apparent conductivity of samples from C1; black: samples from D1; blue: samples from D2.

The linear plots in the Arrhenius graph confirm that at constant field, the conductivity follows the function:

$\sigma=K * e^{\frac{-E_{a}}{K_{B} * T}}$

Where $E_{a}$ is the activation energy, $K_{B}$ is the Boltzmann constant, $T$ is temperature in Kelvin and $K$ is a constant at a constant field.

The average of measurements from all samples of both cables and radiuses at different temperatures and times together with the average of activation energy obtained from the measurements presented in Fig. 7 and Fig. 8 is calculated according to Eq. 2 and is presented in Table 1 .

In both cables, the outer parts show lower activation energy than the inner parts but for $\mathrm{C} 2$ the difference is larger. While the samples from the inner parts of the two cables show similar conductivity level and activation energy, the conductivity level and activation energy of the outer parts differ substantially. This means that a very different field distribution and average conduction behavior can be expected for the two cables.

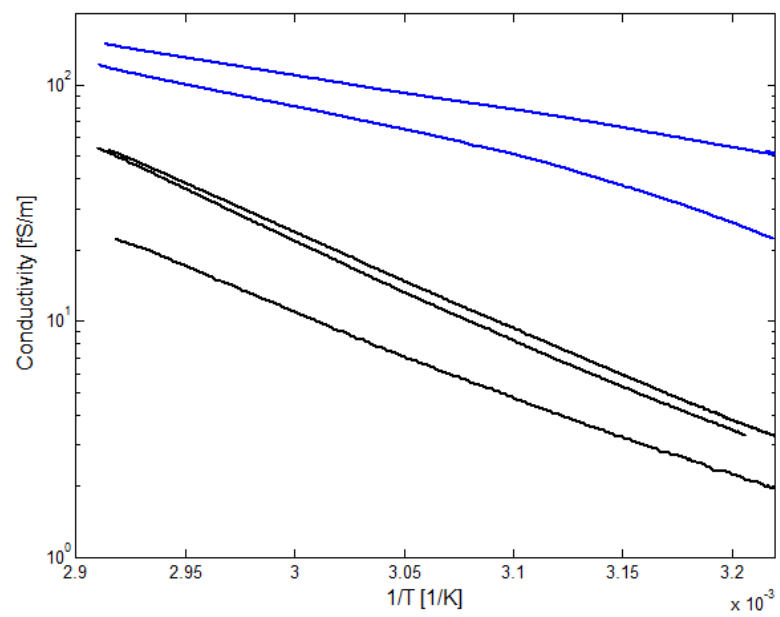

Fig. 8 - Arrhenius plot of apparent conductivity of samples from C2; black: samples from D1; blue: samples from D2.

Table 1 - Average of measured conductivity (in $[\mathrm{fS} / \mathrm{m}]$ ) and activation energy (in $[\mathrm{J}]$ ) for each cable/radius

\begin{tabular}{|c|c|c|c|c|c|c|}
\hline $\begin{array}{c}\text { Cable/ } \\
\text { Radius }\end{array}$ & $\begin{array}{c}70{ }^{\circ} \mathrm{C} \\
12 \mathrm{~h}\end{array}$ & $\begin{array}{c}70{ }^{\circ} \mathrm{C} \\
18 \mathrm{~h}\end{array}$ & $55^{\circ} \mathrm{C}$ & $45^{\circ} \mathrm{C}$ & $40^{\circ} \mathrm{C}$ & Ea [J] \\
\hline C1D1 & 52,8 & 42,9 & 11,6 & 5 & 3,5 & $1,28 \mathrm{e}-19$ \\
\hline C1D2 & 26,5 & 22,4 & 3,8 & 1,1 & 0,8 & $1,8 \mathrm{e}-19$ \\
\hline C2D1 & 67,9 & 53,4 & 12,1 & 4 & 3,7 & $1,55 \mathrm{e}-19$ \\
\hline $\mathrm{C} 2 \mathrm{D} 2$ & 134,4 & 105,4 & 50,4 & 34,8 & 27,5 & $6,5 \mathrm{e}-20$ \\
\hline
\end{tabular}

To compare these results with full-scale measurements, it is possible to estimate the cables average conductivity using the measurements of plaque samples. Since the thermal dependence of conductivity at positions D1 and D2 is known, it is possible to estimate the thermal dependence of the conductivity at all other radiuses using interpolation of the constants $\mathrm{K}$ and $\mathrm{E}_{\mathrm{a}}$. For radiuses less than D1 the same constants as for D1 is used and for radiuses larger than D2 the same constants as D2 is used. Neglecting the field dependence of conductivity, it is then possible to estimate the average conductivity of $\mathrm{C} 1$ and $\mathrm{C} 2$ at $25{ }^{\circ} \mathrm{C}$ and $70{ }^{\circ} \mathrm{C}$ with a realistic temperature gradient over the insulation; in this case a temperature drop of $7,4{ }^{\circ} \mathrm{C}$, over the insulation was estimated from the testing conditions. The results of this estimation is presented in Table 2 together with the actual measurements obtained from the full-scale testing of the cables.

Table 2 - Estimated average conductivity of the $\mathrm{C} 1$ and $\mathrm{C} 2$ using the measurement at D1 and D2, in comparison with the actual results of full-scale measurements.

\begin{tabular}{|c|c|c|c|c|}
\hline Cable & $\begin{array}{c}70{ }^{\circ} \mathrm{C} \\
\text { estimation }\end{array}$ & $\begin{array}{c}25^{\circ} \mathrm{C} \\
\text { estimation }\end{array}$ & $\begin{array}{c}70{ }^{\circ} \mathrm{C} \\
\text { Measured }\end{array}$ & $\begin{array}{c}25^{\circ} \mathrm{C} \\
\text { Measured }\end{array}$ \\
\hline $\mathrm{C} 1$ & 21.8 & 0.2 & 82 & 2 \\
\hline $\mathrm{C} 2$ & 71.8 & 1.1 & 133 & 2 \\
\hline
\end{tabular}

The estimations are slightly lower than the measurements; this can be attributed to the neglected field dependence of conductivity in the estimations. For $\mathrm{C} 2$, the estimation is very similar to the actual measurements except for a factor of 2 difference. For 
$\mathrm{C} 1$ the difference is a slightly larger especially for room temperature results; this can be attributed to the accuracy of the small scale and full scale measurements of very low leakage current levels at room temperature.

The general, conclusion from this rough comparison, is that the results obtained from small scale testing of plaque samples extracted from cables, is in good agreement with the full-scale measurements of the cables. This means that analysis of thick plate samples extracted from HVDC cables can be used for characterization of electrical properties of the insulation; besides such methods can also be used as quality control techniques to assure the right conduction properties of the produced cables which otherwise would be very complicated and costly to assess.

It is obvious that performing this measurement at more number of radiuses would provide more information which would make the conductivity fit more accurate. Besides, the electrical field dependence of conductivity can be measured either from extracted plate samples or from full-scale tests. In this way an accurate empirical conductivity function can be stablished for a cable which may be used to simulate the electric field distribution of at different conditions.

\section{Conclusions}

In this paper, a method for extraction of samples from cables with minimal disturbance to their chemical composition is presented. Thermal, chemical and electrical investigations are done to evaluate the accuracy of this technique.

The chemical measurements confirm that by using this technique, it is possible to obtain samples from XLPE cables without disturbing the by-product concentration of the insulation.

Samples from two cables were extracted from inner and outer parts of the insulation and their DC conductivity was measured at different thermal conditions. The results show that subtle differences in the cables can be detected using this technique.

Analysis of the results and comparison to full-scale measurements, show good agreement between the results of extracted plaque samples and the full-scale measurements results. Considering the simplicity of this technique, it can be used in electrical characterization of extruded cables and also to assess the quality of HVDC cables.

\section{References}

[1] Ghorbani, H.; Jeroense, M.; Olsson, C.-O.; Saltzer, M., "HVDC Cable SystemsHighlighting Extruded Technology," Power Delivery, IEEE Transactions on, vol.29, no.1, pp.414,421, Feb. 2014.

[2] A. Gustafsson, M. Jeroense, H. Ghorbani, T. Quist, M. Saltzer, A. Farkas, F. Axelsson, V. Mondiet, 2015, "Qualification of an extruded HVDC cable system at $525 \mathrm{kV}$ ", presented at JiCable 15, Paris, France.
[3] H. Ghorbani, C.-O. Olsson, J. Andersson, V. Englund, "Robust characterization of the DCconductivity of HVDC insulation materials at high electric fields", JICABLE 15, June 2015, Paper D5.1.

[4] N. Zebouchi, P. Carstensen, A. A. Farkas, A. Campus, and U. H. Nilsson, "Electric Characterization of Films Peeled from the Insulation of Extruded HVDC Cables," in Conference on Electrical Insulation and Dielectric Phenomena, Nashville, Tennessee, USA, 2005.

[5] Hirai, N.; Minami, R.; Ohki, Y.; Okashita, M.; Maeno, T., "Effects of byproducts of dicumyl peroxide on space charge formation in
polyethylene," Solid Dielectrics, 2001. ICSD '01.

[6] N. Hussin, "The effect of crosslinking byproducts on the electrical properties of low density polyethylene", Thesis, 2011.

[7] M. Ieda, T. Mizutani, and Y. Suzuoki, "TSC and TL studies of carrier trapping in insulating polymers", Mem. Fac. Engin. 32 (2), 173 (1980).

[8] Asfour, A.-F. A., Saleem, M., Kee, D. D. and Harrison, B. H. (1989), Diffusion of saturated hydrocarbons in low density polyethylene (LDPE) films. J. Appl. Polym. Sci., 38: 1503-1514.

[9] Solubility and diffusion of water in low-density polyethylene; D. W. McCall, Dean C. Douglass, L. L. Blyler Jr., G. E. Johnson, Lynn W. Jelinski, and H. E. ; Macromolecules 198417 (9), 16441649BairQ. Zhu, K. Wu, H. Wang, W. Xia, S. Lv "The study of PEA space charge waveform recovery under temperaure gradient", ICSD Bologna, 2013

[10] J. C. Fothergill, G. C. Montanari, G. C. Stevens, C. Laurent, G. Teyssedre, L. A. Dissado, U. H. Nilsson, and G. Platbrood, "Electrical, mocrostrustural, physical and chemical characterization of HV XLPE cable peelings for an electrical aging diagnostic data base," IEEE Trans. Dielectr. Electr. Insul., Vol. 10, pp. 514-27, 2003

[11] A. Tzimas, S.M. Rowland, L. A. Dissado, Fu Mingli, and U. H. Nilsson, "Effect of long-time electrical and thermal stresses upon the endurance capability of cable insulation material", IEEE Trans. Dielectr. Electr. Insul., Vol. 16, pp. 14361443, 2009

[12] Dissado, L.A.; Fothergill, J.C.; See, A.; Stevens, G.C.; Markey, L.; Laurent, C.; Teyssedre, G.; Nilsson, U.H.; Platbrood, G.; Montanari, G.C., "Characterizing HV XLPE cables by electrical, chemical and microstructural measurements on cable peeling: effects of surface roughness, thermal treatment and peeling location," Electrical Insulation and Dielectric Phenomena, 2000 Annual Report Conference on, vol.1, no., pp.136,140 vol.1, 2000 . 